\title{
An Application of the "Harmony-Guided Criteria" to the English translation of Song ci: A Case Study of "Immortals at the Magpie Bridge" by Qin Guan
}

\author{
Wang Feng ${ }^{1} \&$ Huang Hongxia ${ }^{2}$ \\ ${ }^{1}$ School of Foreign Studies, Yangtze University, Jingzhou, People's Republic of China \\ ${ }^{2}$ Xiangcheng No. 3 Experimental Middle School, Xiangcheng District, Suzhou City, Jiangsu Province, People's \\ Republic of China \\ Correspondence: Huang Hongxia, No. 3 Experimental Middle School, Xiangcheng District, Suzhou City, Jiangsu \\ Province, People's Republic of China. 215100. E-mail: 598161011@qq.com
}

Received: July 27, 2020; Accepted: August 18, 2020; Online Published: September 1, 2020

This work was supported by the China Scholarship Council under Grant [201808420043].

\begin{abstract}
Ezra Pound's Cathay set the stage for a translation of free verse and influenced many translators such as Arthur Waley and Kenneth Rexroth. However, before Pound, rhymed Chinese poems were mainly translated into rhymed English poems by Herbert Giles, W. J. B. Fletcher, etc. Is it necessary to challenge the dominant translation poetics of free verse and insist that rhymed Chinese poems are best translated into rhymed English poems? Six English versions of a Song $c i$ poem "Immortals at the Magpie Bridge" on the Chinese Valentine's Day were analyzed in details based on the newly proposed "Harmony-Guided Criteria" for poetry translation, which takes "Harmony" as the translation standard at the macro level, "resemblance in style, sense and poetic realm" at the middle level, and the "eight beauties of poetry translation" at the micro level. It shows that the criteria can be applied to the translation of rhymed Chinese $c i$ poems into rhymed English poems, though with limitations.
\end{abstract}

Keywords: Harmony-Guided Criteria, poetry translation, Song $c i$, rhyme, free verse

\section{Epigraph}

Immortals at the Magpie Bridge ${ }^{1}$

By Qin Guan (1049-1100)

Trans. by the authors

Thin clouds are making works of art;

Flying stars bear sorrow at heart;

Across the River of Stars quietly Cowherd meets Weaver.

The reunion tonight when breeze is golden and dew like jade

Just makes, and yet, all the love in the mundane world fade.

Their love is like a tender stream;

The short gathering seems a dream;

They bear not to look back at the Magpie Bridge behind.

As long as there is an eternal love in their mind,

Why must they live together day and night like mankind?

Note 1: This tune name "Immortals at the Magpie Bridge" derives from a Chinese legend about the love between the Cowherd and Weaver, separated by the River of Stars in the sky but allowed to meet only once at the seventh night of the seventh Chinese lunar month in a year at the bridge formed by magpies that sympathize with them. This day is also called Chinese Valentine's Day. 


\section{Introduction}

The Tang poetry and Song $\mathrm{Ci}^{1}$, with their condensed words, catchy rhymes and various emotions, are shining pearls in the history of ancient Chinese literature. With the characteristics of implicitness, conciseness, rich imagery and profound artistic conceptions, their "voice, diction and verb aspects" are ambiguous and difficult to resolve (Shupala, 2000, 14). For more than a century, scholars and translators have researched unremittingly on the translation of ancient Chinese poetry to give these works a second life in the world. According to historical records, the English translation of classical Chinese poetry began in the sixteenth century with a history of more than 400 years. In 1589, a simple introduction to classical Chinese poetry and two English translations of Chinese poems first appeared in The Arte of English Poesie by an English writer and literary critic George Puttenham (c. 15291590). In 1762, Thomas Percy (1729-1811) published a two-volume collection of sinological essays (mostly translations) entitled Miscellaneous Pieces Relating to the Chinese. Sir William Jones (1746-1794) translated several stanzas in The Book of Songs into heroic couplets. John Francis Davis (1795-1890) introduced in more detail the rhyming patterns of classical Chinese poetry and translated poems with interlaced rhymes. Later, James Legge (1814-1897) translated The Book of Songs in prose and rhymed verse in 1871 and 1876 respectively. Addressing Chinese poetry as "Dear Land of Flowers" and "gems", Herbert A. Giles (1845-1935) rendered about 200 Chinese poems into regulated English verses. Such metrical translation was followed by Launcelot Alfred Cranmer-Byng, Charles Budd, W. J. B. Fletcher, Edward Harper Parker, William A. P. Martin, Henry Hart, James Whitall, among others.

Formal verse forms prevailed for much of this literature's translation history. One translator, John Turner, explained that he used rhyme "in an attempt to preserve the singing or musical quality in Chinese," whose "rhyming and metrical systems are more purely wrought and exquisite than any other" (Turner, 1976, xxv). It's true that "Rhyme is the native condition of lyric verse in English; a rhymeless lyric is a maimed thing" (Swinburne, 1875, 162). From the 1980s on, this way of translating classical Chinese poetry into rhymed verse was also advocated and practiced by the majority of Chinese poetry translators (especially those in mainland China) led by Prof. Xu Yuanchong. He insists that "a verse translation should be faithful to the original, less in form than in sense," and that "a poetic translation should be as beautiful as the original in sense, in sound and, if possible, in form" (Xu, 1987, 6). Other major translators include Wu Juntao, Wang Rongpei, Zhuo Zhenying, Zhao Yanchun, etc. As a matter of fact, rhyme is the earliest and most basic aesthetic attribute in classical Chinese poetry. Thus, rendering rhyming Chinese into unrhymed English means writing off the inevitable loss without the recompense of a viable alternative (Kwong, 2009, 214). As Wu Juntao, a well-established Chinese translator of classical Chinese poetry, points out, "Poetry should be translated into poetry rather than prose. If it's metrical, don't translate it into free verse. Metrics are not shackles but rules of dance. There are rules for waltz, tango, foxtrot, etc. and a good dancer will not feel shackled when he dances by rules" (Wu, 2011, 5).

On the other hand, most native English translators, greatly influenced by Ezra Pound, have moved away from rhymed translations from the 1910s on. While Pound's impact has been explored elsewhere at length, a brief review is in order. The modernist poet Pound published Cathay, in which he translated into English a total of 19 ancient Chinese poems spanning from the 11th Century BCE to 4th Century CE, based on Ernest Fenollosa's notes. In his bold translations from Chinese with which he was unfamiliar, Pound set the stage for a translation of free verse and influenced many translators, including Amy Lowell, Florence Ayscough, Rewi Alley, A. C. Graham, Kenneth Rexroth, Burton Watson, Gary Snyder, David Hinton, Stephen Owen, Yang Xianyi \& Gladys Yang (sometimes in verse translation), etc. Translators following the aesthetic of unrhymed verse have put forth different arguments. Pound, for example, argued, "One discards rhyme, not because one is incapable of rhyming neat, fleet, sweet, meet, treat, eat, feet but because there are certain emotions or energies which are not represented by the over-familiar devices or patterns" (Pound, 1915, 277). Arthur Waley believes that "rhymes are so scarce in English (as compared with Chinese) that a rhymed translation can only be a paraphrase and is apt to fall back on feeble padding" (Waley, 1918, 19). Stephen Owen states, "There is also no way to echo the forms of Chinese poetry and still produce translations that are accurate and readable" (Owen, 1996, xliv).

Generally speaking, in translating classical Chinese poetry into English, earlier English native translators preferred rhymed English verses; however, around the time of Imagism, formal verse began to fall out of favor in the AngloAmerican polysystem. After that, most of the English native translators and Chinese-American translators are prone to use free verses, while the majority of Chinese translators still advocate translating rhymed Chinese poems into rhymed English verses. Such a divergence in translation poetics has been existent for about one hundred years; thus, it needs more discussion and even hot debates, between Chinese and western poetry translators and critics to face the question: should rhymed Chinese poems be translated into rhymed English poems? 


\section{Translating Rhymed Chinese Poems into Rhymed English Poems}

As a matter of fact, most well-known translators of the Tang poetry and Song $c i$ such as Florence Ascough, Amy Lowell, Burton Watson and David Hinton have followed the free verse approach started by Ezra Pound, Arthur Waley, etc., even though Pound is only "the inventor of Chinese poetry" rather than "a translator of Chinese poetry" in the strict sense (Eliot, 1928, xvii). They all reject rhyme, opting for the free verse that they think would better capture the spirit of the original. This fact probably lies in that the "literary cost/benefit ratio" of translating a poem into a rhymed version today is too unfavorable, considering the perceived tediousness of the task and the dominant anglophone poetics of free verse (Hanson, 1992, 32). However, Schulte advocated that "[i]t is time that we transcend the visual appearance of words on the page toward the inherent tonal quality underlying words as sound spaces. The exploration of the sound material of poetic and fictional works must become the future challenge of critical and scholarly investigations and treatizes" (Schulte, 2008, 1).

To better achieve formal adequacy, we hold that rhymed poems should be translated into rhymed poems. Barnstone admits that "[t]he Chinese call the methods of the great Tang poets of working imaginatively while being bound by STRICTURES' dancing in chains'" (Barnstone, 1993, 270). In addition, as the conversation between Sibelan Forrester and poet Daisy Fried shows,

Of course, rhymed and metrical language is widely present today in anglophone popular culture: popular music still exploits those pleasures as it crafts "earworms", and the heightened verbal elements of rap music can edge into spoken-word poetry, which prizes rhyme - sometimes elaborate - and often generates meaning through paranomasia. Moreover, anglophone verse from the nineteenth century and before (Shakespeare, Dickinson, etc., with their relatively more traditional forms and rhymes) still attracts many readers. Practicing poets in the United States today may say with wry amusement that their children refer to rhymed poetry as "real poetry". (Fried, 2014, 187188)

Moreover, the suitability of English as a language for writing rhyming, scanning poetry is invoked not only in discussions of translation, but also in scholarship about and reviews of anglophone poetry per se. (Forrester, 2018, 188.) In light of the fact that the Tang poetry and Song $c i$ has fixed rhyme and tone schemes, we contend that it is better to reproduce the musicality in the target language, which is widely supported by thousands of Chinese translators and scholars such as Xu Yuanchong, Wu Juntao, Sun Dayu, Wang Yushu and Liu Junping (Wang, 2015, 88). Kates believes that "A translation should at least shadow, even where it cannot reflect, its original. It may not be a full portrait, but it can be at least an artful silhouette" (Kates, 2008, xviii). In history, many translators have been determined to translate rhymed poems from a foreign language into rhymed English poems, as exemplified by Edward Fitzgerald's Khayyam, Rossetti's Villon, Nims's St. John of the Cross, Untermeyer's Heine, Ciardi's Dante, etc.

\section{Harmony-Guided Criteria for Poetry Translation}

If we believe that rhymed Chinese poems should be translated into rhymed English poems, the second and more important question is how rhymed Chinese poems can be better translated into rhymed English poems. Dahlgren adopted a relevance-based approach to analyze poems in translation (Dahlgren, 2000, 97-108). Mateo believed that the target text should convey a presumption of relevance similar to that of the original text (é Mateo, 2009, 112). However, it is often claimed that the evaluation of translated poetry is a subjective affair and that no method can account for what is preserved, gained and lost in translation. Enlightened by predecessors' literary translation theories, a set of poetry translation criteria were put forward to guide poetry translation and poetry translation criticism, which is named the "Harmony-Guided Criteria" for poetry translation. It has been successfully applied in his monograph to the analysis of English versions of Tang poems to ensure translation quality, especially that of rhymed translation (Wang, 2015, 144-152). In this article, the authors aim to broaden its research object to Song $c i$ and to explore the rationality and applicability of the "Harmony-Guided Criteria" for poetry translation as a standard for $c i$ translation and $c i$ translation criticism.

Needless to say, great differences between Chinese and English have been deeply reflected in their cultures. To translate Song $c i$ into English, one must understand the differences. In the face of the disharmonies between the two languages and cultures, Wang put forward the "Harmony-Guided Criteria" for poetry translation -- "Harmony" as the translation standard at the macro level, "resemblance in style, sense and poetic realm" at the middle level and the "eight beauties of poetry translation" at the micro level (ibid.).

At the macro level, the basic idea is the notion of "Harmony", which is similar in meaning to "equilibrium" and mainly based on The Book of Rites: Doctrine of the Mean: 
[T]he superior man is watchful over himself, when he is alone. While there are no stirrings of pleasure, anger, sorrow, or joy, the mind may be in the state of Equilibrium. When those feelings have been stirred, and they act in their due degree, there ensues what may be called the state of Harmony. This Equilibrium is the great root from which grow all the human actings in the world, and this Harmony is the universal path which they all should pursue. Let the states of Equilibrium and Harmony exist in perfection, and a happy order will prevail throughout heaven and earth, and all things will be nourished and flourish. (Legge, 2017, 1.)

This notion of "Harmony" has been illustrated (Zheng, 2000, 136-165), but not applied in poetry translation studies At the middle level, inspired by ancient Chinese poetics and certain translation standards held by accomplished translators, the criteria of "resemblance in style, sense and poetic realm" are put forward, which insist that the style, sense and poetic realm of the target text should be similar to those of the source text. At the micro level, drawing on Xu Yuanchong's "Three Beauties" theory (Xu, 2006, 73), Gu Zhengkun's poetry appreciation theory (Gu, 1998), Lin Yutang's "Five Beauties' theory (Lin, 1987) and Peter Newmark's translation aesthetic views (Newmark, 2001, 94-103), Wang proposed the "eight beauties of poetry translation". It should be noted that "beauty" has been a loaded term in Western cultures for at least two centuries, and in Chinese culture, it has also been studied for more than a thousand years. There are hundreds of definitions of beauty. However, as the authors aim to study "beauty" specifically in terms of its major components, "beauty" includes the diction, structure, discourse, artistic characteristics embodied in its metrical pattern, images, poetic realm, etc., and is composed of the following eight specific beauties, which are listed as follows: 1) the beauty of form, exemplified in the regular number of lines, arrangement and length of lines; 2) the beauty of musicality, shown in the Chinese level-deflected tones or English rhyme and rhythm; 3 ) the beauty of images, composed of vivid images or perceptual components of the imaginary groups in reality or imagination; 4) the beauty of emotions, including joy, anger, sorrow, love, hatred and regret; 5 ) the beauty of diction, which is often embodied in several most important words to express the poet's thoughts and feelings; 6) the beauty of suggestiveness, which is typical in Chinese poetry, referring to an exquisite poetic technique of implicitly showing the poet's emotions or ideas while not mentioning any words directly related to them; 7) the beauty of allusions, which can make artistic works concise but possibly puzzle readers in some cases because they are related to historical legends, events, stories, figures, or expressions; and 8) the beauty of gestalt, which refers to all other beauties less frequently noticed except for the aforementioned seven beauties on the one hand, and all the beauties combined together on the other. With the three-level approach, the "Harmony-Guided Criteria" for poetry translation combines the general and the particular, so that it can hopefully better guide the translation of Chinese poetry into rhymed English poems, even though the three levels cannot be distinctly separated from one another.

\section{Qin Guan and His Song $c i$ - "Immortals at the Magpie Bridge"}

Qin Guan (1049 - 1100) was a writer and poet in the Northern Song Dynasty and was honored as the master of $c i$ of the Romantic school. He was talented in $c i$ and his works were often concerned with love between men and women; sometimes he also wrote about his sentimental life. The style of this $c i$ is implicit, subtle and elegant. The Chinese text of the Song $c i$ is:

\section{秦观《鹊桥仙》}

纤云弄巧, 飞星传恨, 银汉迢迢暗度。金风玉露一相逢, 便胜却人间无数。柔情似水, 佳期如梦, 忍 顾鹊桥归路！两情若是久长时, 又岂在朝朝暮暮！

"Immortals at the Magpie Bridge" is not a title but a tune name, which determines its pattern and form. The source of the tune usually covers the names of other songs, previous poems, allusions, a person's name or a place name, the content or important words from the $c i$, etc. With its rich connotation, a tune name provides us with aesthetic imagination and aesthetic enjoyment ( $\mathrm{Li}, 2005,49-53)$. The upper and lower stanzas of the $c i$ describe the scene of the Cowherd and Weaver's meeting and the departure at the seventh night of the seventh Chinese lunar month each year (This date is later called the Chinese Valentine's Day, but certainly with different cultural connotations from the western Valentine's Day). The $c i$ shows authentic emotions with vivid scenery description, natural disposition and artistic expressions, earning the composition a long-standing reputation and great popularity. It is true that there have been many works depicting the joys and sorrows of the Cowherd and Weaver in ancient times, but most of them are in a plaintive and mournful style. However, this $c i$ is "a denial of the vulgar life of happiness, and it is an ode to the everlasting love of loyalty," whose true meaning is "As long as there is an eternal love in their hearts, why must they stay together day and night like mankind?" (He, 2015, 191-193) Its ingenious literary conceits are far beyond other poetic works of the same kind. 


\subsection{An Analysis of Six English Versions of "Immortals at the Magpie Bridge"}

There are about twenty published English translations of "Immortals at the Magpie Bridge". However, we can only limit our discussion to six by better-known translators, namely, Xu Yuanchong (hereinafter referred to as XYZ), Zhao Yanchun (Zhao), Zhuo Zhenying (Zhuo), Xu Zhongjie (Xu), Alan Ayling and Duncan Mackintosh (A\&M) and Qiu Xiaolong (Qiu) a Chinese-American. The translations are further divided into two categories: metrical verses (XYZ, Zhao, Zhuo) and free verses (Xu, A\&M, Qiu). Under the "Harmony-Guided Criteria" for poetry translation, the six English versions of "Immortals at the Magpie Bridge" by Qin Guan are studied.

\subsection{The Macro-level: Harmony}

As the English translation of this Song $c i$ faces the linguistic and cultural differences between English and Chinese, translators are supposed to bear in mind the concept of "Harmony". Harmony at the macro-level can provide a macro perspective to the translation of Song $c i$. When it comes to "Immortals at the Magpie Bridge" by Qin Guan, translators attend to its artistic, lyric, metrical and tonal characteristics, and take into consideration the Chinese mode of parataxis, etc. For example, where the difference between parataxis and hypotaxis is concerned, the Chinese original did not clearly explain who are crossing the River of Stars, which highlighted the conciseness of classical Chinese poetry and its characteristic absence of grammatical signs, requiring the translators to reproduce in the target language its voice, subject, verb aspect, etc. (Shupala, 2000, 14-19). Therefore, by taking "Harmony" as the macro translation criterion to reach the Equilibrium between parataxis and hypotaxis, translators can retain the original poetic flavor and cater for readers' aesthetic experience in translation at the same time.

\subsection{The Middle-level: Resemblance in Style, Sense and Poetic Realm}

Moving between tongues, translation acquires difference (Barnstone, 1993, 265). However, it is still the translator's task to negotiate the difference and achieve resemblance in style, sense and poetic realm, which we will define below. Translators need to conduct biographical analysis, contextualization of the writer's socio-cultural environment, literary inquiry and (not necessarily) comparative readings of translations and/or original texts (Facchi, 2018: 1).

\section{1) Resemblance in Style}

Literary style is embodied in selecting the genre, theme and language usage, reflecting the writers' creative personality and thoughts (Zhuo, 2003, 31). To be more specific, one author's style is manifested in his/her diction, sentence structure, rhetoric, rhyme, rhythm, textual structure, imagery, artistic conception, etc. Qin Guan's "Immortals at the Magpie Bridge" has lyric, narrative and argumentative expressions in many segments. However, for example, Qiu's translation has many enjambments. The translation can be considered a good poem by itself, but its style is different from the original.

\section{2) Resemblance in Sense}

Poetic sense is a description of the reality or imagination by the poet in an artistic way, inviting the reader's understanding, imagination and emotions. Jiří Levý claims that the preservation of semantic functions is of a higher order than rhyme (Levý, 1969, 10). Gadamer also emphasizes the importance of meaning in stating that the translator must translate the meaning to be understood into the context in which the other speaker lives (Gadamer, 1992, 384). In "Immortals at the Magpie Bridge", Qin Guan used fifty-six words to describe the delightful meeting and sorrowful departure of the Cowherd and Weaver, but only "they/their" is used in both versions of Zhao and $\mathrm{Xu}$ to refer to the two immortals without annotation. However, "trying to translate the specific expression in the high context culture directly to a low context culture usually causes readers' difficulty in understanding the translation" (Wang, 2015, 151). The versions of Zhuo and Qiu can help readers better understand the poetic sense because they added annotations to interpret the story of the Cowherd and Weaver.

\section{3) Resemblance in Poetic Realm}

The poetic realm is what Ezra Pound called ideorealm and what other Chinese scholars called artistic conception. It is the poetic state in which the poet's feelings are manifested through various groups of images in a certain context. In "银汉迢迢暗度" (Across the River of Stars quietly Cowherd meets Weaver), "银汉" literally means the "Silver River" and is usually called the "River of Stars". However, XYZ, Zhuo, Xu, A\&M and Qiu adopted the domesticating strategy to translate "银汉" into "the Milky Way". In fact, the connotation of "银汉" (Silver River) in Chinese culture is totally different from that of "Milky Way" in Western culture. ${ }^{2}$ It's also a common sense that a "river" (as in the Silver River) can stop two people meeting each other, while a "way" (as in the Milky Way) usually connects people. Therefore, translators should not always adopt the strategy of domestication to reduce the exotic factors in translation, which will hinder the readers from experiencing the poem's exotic flavor. As Venuti points out, translators should be "determined to take responsibility for bringing a foreign text into a 
different situation" (Venuti, 2011, 246). Although there are many differences between the two languages and cultures, translators can make constant efforts to adopt appropriate translation strategies and methods to make readers understand the original poetic and artistic realm (Liu, 1991, 72). Therefore, "银汉" is better not translated into "the Milky Way", but literally into "the Silver River", or "the River of Stars" with an explanation. At this specific point, Zhao's translation is better in reproducing the poetic realm in the target language and culture.

\subsection{The Micro-level: Eight Beauties}

According to Barnstone, foremost among fidelities is fidelity to beauty in the original poem (Barnstone, 1993, 269). Classical Chinese poetry and Song $c i$ have almost all the characteristics of beauty. Discussion at the macro and middle levels are still too abstract to make readers clearly understand the difference between different translations. It's necessary to analyze the different versions in terms of the eight specific beauties mentioned above.

\section{1) The Beauty of Form}

Meter and rhyme are at the core of regulated poetry; thus, these formal features should be reproduced in the target culture, even at the risk of making the readers less comfortable (Muchnick, 2009, xi). There are ten segments in "Immortals at the Magpie Bridge", which are divided into the upper and lower stanzas with five segments respectively and their third and fifth segments are in rhyme. The number of words in each stanza is 4, 4, 6, 7, 3, 4 . As for the words, XYZ, Zhuo, Zhao and Qiu's English versions have relatively fewer words. However, Xu's version has more words, which make the sense and rhythm less intense. In translation, the number of words in translation should not be too different from that in the original text. As for the number of poetic lines, XYZ, Zhao, Zhuo and A\&M's translations have ten lines, which can better reproduce the original ten segments, while Xu's version has eighteen lines and Qiu's fifteen lines.

2) The Beauty of Musicality

The earliest $c i$ refers to lyrics that can be sung with music. Musicality plays an important role in $c i$. However, as Dahlgren pointed out, "[t]he obviation of elements of phonological meaning and a concentration on syntactic and lexical meaning have produced inappropriate renderings in the target language" (Dahlgren, 2000, 107). Schulte also pointed out that $[\mathrm{m}]$ ost scholarship has ignored the treatment of how language and meaning come to flourish through the sound material of a language (Schulte, 2008, 2). In fact, the beauty of musicality is often complementary and inseparable from that of form. Like classical Chinese poetry (especially metrical poetry and $c i$ ), traditional English poetry (except for blank verse) also boasts the beauty of rhyme and rhythm. The rhyming schemes in the versions of XYZ, Zhuo and Zhao are: aabbb ccdd aabbb ccdd; aaabb ccdd, while Xu's is aaaa bbcc dd eeff gghh. These four translations are quite sonorous and rhythmic, especially the first three. Regarding the rhythm, the number of syllables of each line in the versions of XYZ, Zhuo and Zhao are 6, 6, 12, 12, 12; 8, 8, 10, 10,$10 ; 9,9,12,12,12,10,10,12,12,13 ; 6,6,9,10,10,6,6,9,10,10$, forming different numbers of iambic or trochaic feet to represent the original $c i$ 's musicality. However, the versions of A\&M, Xu and Qiu lack obvious rhythm and musicality. Thus, among the six versions, the versions of XYZ, Zhao and Zhuo better reproduced the beauty of musicality. Certainly, we need to be aware that the beauty of musicality does not always have to be reproduced, lest there be much loss of meaning (Gu, 1994, 73).

\section{3) The Beauty of Images}

There are many images in "Immortals at the Magpie Bridge", including "thin clouds", "flying stars", "golden breeze", "jade-like dew" and the "Magpie Bridge". Except for the translation of "银汉" (Silver River) mentioned above, the six translations appropriately dealt with the remaining images. As the original $c i$ implied the two images of the Cowherd and Weaver, translators are supposed to make up for the hidden and implied images in translation. In Xu's version, it is not clear what "Laddie" and "Lassie" refer to; "the Maid" in XYZ's translation is also ambiguous; "they/their" in Zhao's version is also of much vagueness. "The Maid subtly weaves" in the first line of Zhuo's translation highlights the image of the Weaver. In the versions of Qiu, he uses the "Weaving Girl" and "Weaver" to refer to the heroine respectively. In comparison, the latter two translations mentioned above are better in reproducing the images of the main character.

In addition, the translation of the tune name cannot be underestimated as it includes quite meaningful images in this $c i$. Actually, the tune name means the gathering and parting of the Cowherd and Weaver, which is closely related to the theme. Xu translated it into "Queqiaoxian" by transliteration, but it does not make much sense to target readers, because transliteration does not necessarily bring about the meaning or the conciseness of language; sometimes it needs readers to consider the context to guess its meaning. However, not every reader has such expertise to do it. A\&M also transliterated the title into the unintelligible "Ch'ueh Ch'iao Hsien", but their addition of an explanation "the Weaver-Girl and the Herd-Boy" clarified the meaning. XYZ, Zhao and Zhuo translated the 
tune name into "Immortal at the Magpie Bridge", "Immortals on the Magpie Bridge" and "The Immortal Magpie Bridge" respectively in literal translation, while Qiu paraphrased it into "The Seventh Night of the Seventh Moon" and "Meeting across the Milky Way". Among them, the use of the plural "Immortals" rather than the singular "Immortal" reflected that there are actually two characters meeting at the Magpie Bridge. In addition, "The Seventh Night of the Seventh Moon" told us the time when the meeting happens, but failed to reproduce the original images.

Additionally, by portraying the images of "thin clouds", "flying stars", "River of Stars", "golden breeze" and "jadelike dew", this $c i$ highlights the two immortals' rare meeting, rendering a sad and desolate atmosphere. These images should be reproduced as accurately as possible. However, it's a pity that A\&M added images like "a distant gulf of the Milky Way", "time's abyss" and make the translation quite different from the original.

\section{4) The Beauty of Emotions}

The typical aesthetic characteristic of $c i$ is to share the same feeling and to seek spiritual communion with the poet (Zhang, 2014, 140). If poetry translation just plays a role of conveying meanings more than expressing emotions, it is "not to be called translation, but an assassination of the original text" (Dong, 2004, 52). In the versions of XYZ and Qiu, "忍顾鹊桥归路" (They bear not to look back at the Magpie Bridge behind) was dealt with as an interrogation, while $\mathrm{Xu}$ and $\mathrm{Zhao}$ treated it as an exclamatory sentence. Zhuo changed the perspective, and the feelings were directly reflected in the Cowherd and Weaver's "tears".

5) The Beauty of Suggestiveness

Suggestiveness, or implication, is an important characteristic of ancient Chinese poetry. In dealing with the beauty of suggestiveness, there are usually two approaches. For example, in translating Chinese poems, Waley is closely faithful to the original and allows the deep implication to lie latent for the reader to figure out, while Pound spells out the latent meanings of the poem $(\mathrm{Gu}, 2008,52)$. The poet uses suggestive words to invite readers' imagination to endow the $c i$ with deeper meanings. As we know, the one-year separation between the Cowherd and Weaver after only one day's meeting is absolutely heart-breaking. However, the poet Qin Guan did not explicitly state that it's heart-breaking. The version of Xu is "It is hard for me to look back on the homeward path from the Blackbirds Bridge", in which the word "hard" is too explicit in showing the anxiety of separation. Such a translation is too straightforward to reproduce the implicit beauty of the original $\mathrm{ci}$.

6) The Beauty of Diction

Words' power of communication is related to other words, images, or metaphors (Schulte, 2008: 2). Often, there is no obvious or correct choice and it then becomes a matter of the translator's choice and, where there are alternatives, the reader's preference (Walters, 2018: 5). Classical Chinese poetry attaches great importance to the beauty of diction. The most succinct, vivid and accurate expressions of meanings, emotions and connotations are called the "eye of poetry". The proverb "A miss is as good as a mile" is perfect in demonstrating the importance of the "eye of poetry". Therefore, the meaning of the original $c i$ should also be translated with the best words, though it is not necessarily literal or word-for-word translation. The word "恨" (hatred, literally) in the $c i$ conveys the sorrow of the lovesickness rather than hatred; thus, it cannot be literally translated. XYZ, Zhuo and Zhao used "grief/grieve" to represent the complaints of their affliction. A\&M used "yearnings" while Qiu used "sad message" to show the emotion. "Stars have qualities more wonderful still; / The hopes of their fellows, / The hopes of their fellows" in Xu's version is a little too tedious, failing to accurately convey the hatred of lovesickness. The word " 忍" (bear, literally) implies the helplessness and pain of parting. Thus, in the versions of XYZ, Zhuo and Xu, they used the phrase "bear" and "have the heart" to reveal the heaviness deeply felt in the Cowherd and Weaver's hearts.

\section{7) The Beauty of Allusions}

The use of allusions is a common poetic technique in ancient Chinese poetry. Generally, poets implicitly express their feelings or emotions with the help of historical figures, mythology, fables, and so on. Therefore, to deliver the feelings and emotions of the original poetry or $c i$, translators need to accurately reproduce the allusions in it. In this $c i$, it described the story of the Cowherd and Weaver at the Magpie Bridge; thus, it is necessary to maintain the beauty of allusions. Except for the vague definition of "they/their" referring to the Cowherd and Weaver in $\mathrm{XYZ}$, five of the six translations basically reproduced such a heart-breaking story. Among them, Zhuo and Qiu added annotations, which are helpful for readers to understand their translations as well as the allusion.

8) The Beauty of Gestalt

Gestalt originally means an organized whole that is perceived as more than the sum of its parts. Here it is used to refer to all the remaining beauties left undiscussed as well as the total beauties. As Sullivan pointed out, "successful translation is, therefore, a holistic act, one that demands a total grasp of subject, from overarching concept to the most minuscule detail" (Sullivan, 2008, 13). Except for the above-mentioned seven kinds of beauty, it is better for 
the translated version to reproduce other possible minor or subtle beauties to reproduce all the beauties as a whole, including, but not limited to, the appropriate representation of the part of speech, verb aspect, the repetitive sounds in the line, voice, perspective, etc. It should be noted that, for a specific poem, the beauty of gestalt may or may not include the beauty of using numbers, or the beauty of unbeautifulness, which is especially seen in the works of disturbing poets such as, say, Baudelaire or Leopardi, as well as Chinese poets such as Han Yu, Meng Jiao, or Jia Dao. The concept of gestalt emphasizes that "the whole of perceptual experience is more than the sum of its parts (Wang, 2015, 209). Thus, the beauty of gestalt is not a simple totaling of all the beauties in the original poem. Its reproduction in the target language and culture is profound and worthy of further research.

\section{Conclusion}

The Tang poetry and Song $c i$ are numerous in theme, extensive in content and diverse in artistic form. Through the comparison and analysis of the six English versions of Qin Guan's "Immortals at the Magpie Bridge" under the "Harmony-Guided Criteria" for poetry translation specially constructed to guide rhymed poetry translation, it is not difficult to discover that translators can overcome the disharmonies in poetry translation in light of the "Harmony" at the macro level, "resemblance in style, sense and poetic realm" at the middle level, and the eight specific beauties at the micro level.

Generally speaking, the "Harmony-Guided Criteria" for poetry translation can be used as criteria in the translation of $c i$ into rhymed English poems. Certainly, the criteria also have limitations. Firstly, Chinese and English are different in rhyme, rhythm, images, sense, style, suggestiveness, poetic realm and other textual features. It is still difficult for translators to balance the macro-level, middle-level and micro-level criteria, which are not distinct from one another. Secondly, not all poems contain all the eight beauties; thus, the eight beauties at the micro-level do not necessarily apply to all poems or $c i$, and the rendering of the eight beauties needs to be deliberated according to the characteristics of the original poem or $c i$.

As Hanson pointed out, there is no one correct way to accomplish a translation because it is always a matter of preference (Hanson, 1992, 33). Multiple versions of an important work may be needed at one and the same time to suit various audiences (Forrester, 2018, 197). If we agree with John Balcom in saying that, "each generation must produce its own translation of an important poetic text" (Balcom, 2001, 35), shall we ask ourselves, is it a good try for poetry translators to translate the rhymed Chinese poems into rhymed English poems? If yes, we would recommend this comprehensive "Harmony-Guided Criteria" in translating rhymed Chinese poems into rhymed English poems, disregarding the unfavorable "literary cost/benefit ratio".

\section{References}

Balcom, J. (2001). Big rat, big rat: multiple translations of a Chinese poem, Translation Review, 62(1), 35-41. https://doi.org/10.1080/07374836.2001.10523798

Barnstone, Willis. (1993). The Poetics of Translation. History, Theory, Practice. New Haven: Yale University Press.

Dahlgren, M. (2000). A relevance-based approach to poetry in translation, Perspectives: Studies in Translatology, 8(2), 97-108. https://doi.org/10.1080/0907676X.2000.9961377

Dong, H. (2004). Making translation one of the fine arts -- appreciation of Lin Yutang's English translation of classical Chinese poetry. Journal of Xi'an International Studies University, (1), 52-54.

Eliot, T. S. (1928). Introduction to Selected Poems of Ezra Pound, London: Faber \& Gwyer.

Facchi, F. (2018). Telling the story of translation. writers who translate, The Translator. https://doi.org/10.1080/13556509.2018.1463485

Forrester, S. (2018). Whose foreign is foreign? form and norms of translation of contemporary Russian poetry into English, Translation Studies, 11(2), 185. https://doi.org/10.1080/14781700.2018.1472632

Fried, D. (2014). personal conversation. qtd. in Sibelan Forrester, Whose foreign is foreign? form and norms of translation of contemporary Russian poetry into English.

Gadamer, Hans-Georg. (1992). Truth and Method. Trans. Joel Weinsheimer and Donald G. Marshall. 2nd rev. ed. New York: Crossroad.

Gu, Mingdong (2008). Is Pound a translator of Chinese poetry? Translation Review, 75(1), 47-55. https://doi.org/10.1080/07374836.2008.10523973

Gu, Zhengkun (1998). China and West: Comparative Poetics and Translatology. Beijing: Tsinghua University Press.

Gu, Zhengyang. (1994). My view on English translation of Tang poetry and Song ci. Journal of Shanghai 
University (Social Science Edition), (6): 73-77.

Hanson, H. (1992). The translation of poetry, Translation Review, 28-34. https://doi.org/10.1080/07374836.1992.10523529

$\mathrm{He}$, Sha (2015). Comment on two English versions of Qin Guan's 'Immortals at the Magpie Bridge'. Journal of Chifeng University (Chinese Philosophy and Social Sciences Edition), 36 (5): 191-193.

Kates, J. (2008). Translation editor's note. In Contemporary Russian Poetry: An Anthology, edited by J. Kates, and Evgeny Bunimovich, Champaign, IL: Dalkey Archive Press.

Kwong, C. (2009). Translating classical Chinese poetry into rhymed English: a linguistic-aesthetic view, TTR: Traduction, Terminologie, Redaction, XXII(1), 189-220. https://doi.org/10.7202/044787ar

Legge, J. T. (2017). Doctrine of the Mean, Musaicum Books, p. 1.

Levý, J. (1969). Die literarische Übersetzung: Theorie einer Kunstgattung. Frankfurt: Athenāum.

Li, Qing (2005). On the method of the English translation of Li Qingzhao's ci. National Forum, (4): 49-53.

Mateo, J. (2009). Contrasting relevance in poetry translation, Perspectives: Studies in Translatology, 17(1), 12. https://doi.org/10.1080/09076760902940104

Muchnick, S. C. (2009). Salt Crystals on an Axe: Twentieth-Century Russian Poetry in Congruent Translation: A Bilingual Mini-Anthology. Translated by A. Shafarenko. Godalming: Ancient Purple.

Newmark, P. (2001). Approaches to Translation. Shanghai: Shanghai Foreign Languages Education Press.

Owen, S. (1996). A note on translation, An Anthology of Chinese Literature: Earlier Times to 1911, New York: W. W. Norton.

Pound, E. (1915). Affirmations: As for Imagism, The New Age, January.

Schulte, R. (2008). Editorial: How Should a Translator Walk Through a Text?, Translation Review, 75(1), 2. https://doi.org/10.1080/07374836.2008.10523965

Shupala, A. (2000). Translating classical Chinese poetry without a literal translation. Translation Review, 60(1), 14-19. https://doi.org/10.1080/07374836.2000.10523776

Sullivan, C. (2008). On translating badly: sacrificing authenticity of language in the interest of story and character, Translation Review, 75(1), 13. https://doi.org/10.1080/07374836.2008.10523968

Swinburne, A. C. (1875). Essays and Studies. London: Chatto \& Windus.

Turner, J. T. (1976). A Golden Treasury of Chinese Poetry. Hong Kong: The Chinese University of Hong Kong, xxv.

Venuti, L. (2011). The Poet's Version; Or, An Ethics of Translation, Translation Studies, 4(2), 246. https://doi.org/10.1080/14781700.2011.560021

Waley, A. T. (1918/1962). One Hundred \& Seventy Chinese Poems. London: Constable \& Co.

Walters, G. (2018). Translating the poetry of Salvador Espriu: a review with recommendations, Bulletin of Spanish Studies, 5. https://doi.org/10.1080/14753820.2018.1436231

Wang, Feng (2015). A Comprehensive Study on the English Translation of Classical Tang Poetry. Beijing: China Social Sciences Press.

Wu, J. (2011). Preface. In Wang Feng and Ma Yan, eds. A Critical Anthology of Tang Poems and their English Translations. Xi'an: Shaanxi People's House.

Xie, M. (2011). Contexts in poetic translation: iterability, event, openness, Perspectives: Studies in Translatology. https://doi.org/10.1080/0907676X.2010.514349

Xu, Yuanchong (1987). On Tang poetry and English poetry. In Xu, Y. Loh B. and Wu J., eds., 300 Tang Poems: A New Translation, Hong Kong, The Commercial Press.

$\mathrm{Xu}$, Yuanchong (2006). The Art of Translation. Beijing: Wuzhou Communication Press.

Zhang, Y. (2014). Strategies for the translation of Song $c i$ - centered on Li Qingzhao's Slow Slow Sound. Chinese Culture Research, 140-146.

Zheng, Hailing (2000). Literary Translation. Zhengzhou: Wenxin Press.

Zhuo, Zhenyin (2003). The style of Chinese poetry translation is flexible. Foreign Language and Foreign 
Language Teaching, (10), 31-36.

\section{Notes}

Note 1. The Tang poetry refers to the classical Chinese poetry written in the Tang Dynasty (618-917), often considered as the Golden Age of classical Chinese poetry. Song $c i$, a type of lyric poetry prominent in the Song Dynasty (960-1279), has certain patterns in fixed-tone, fixed-rhyme and variable line-length, forming certain musical song tunes.

Note 2. Chinese people created the love story of Cowherd and Weaver by associating the Cowherd Star (Altair) and the Weaver Star (Vega) on either side of the "River of Stars", which symbolizes the obstruction between lovers in feudal society. In Greek mythology, the Milky Way was formed after the trickster god Hermes suckled the infant Heracles at the breast of Hera, the queen of the gods, while she was asleep. When Hera awoke, she tore Heracles away from her breast and splattered her breast milk across the heavens. In another version of the story, Athena, the patron goddess of heroes, tricked Hera into suckling Heracles voluntarily, but he bit her nipple so hard that she flung him away, spraying milk everywhere. "Milky Way", last modified May 26, 2018. Accessed, June 16, 2019. https://en.wikipedia.org/wiki/Milky_Way\#Etymology_and_mythology.

\section{Copyrights}

Copyright for this article is retained by the author(s), with first publication rights granted to the journal.

This is an open-access article distributed under the terms and conditions of the Creative Commons Attribution license (http://creativecommons.org/licenses/by/4.0/). 